\title{
THE RELATION BETWEEN PUMP FLOW RATE AND PULSATILITY ON CEREBRAL. HEMODYNAMICS DURING PEDIATRIC CARDIOPULMONARY BYPASS
}

Gabriel Chow, MRCPI ${ }^{\mathrm{a}}$

Idris G. Roberts, $\mathrm{BSc}^{\mathrm{a}, \mathrm{e}}$

A. David Edwards, FRCP ${ }^{\mathrm{e}}$

Adrian Lloyd-Thomas, FRCA ${ }^{\mathrm{b}}$

Angie Wade, $\mathrm{MSc}^{\mathrm{c}}$

Martin J. Elliott, FRCS ${ }^{\mathrm{d}}$

Fenella J. Kirkham, FRCP
Objectives: Neurologic impairment, at least partly ischemic in origin, has been reported in up to $25 \%$ of infants undergoing cardiopulmonary bypass, with or without circulatory arrest. Controversy continues about the effect of pump flow, pulsatile or nonpulsatile, on the brain and in particular on cerebral blood flow. This study examines the relationship between pump flow rate and cerebral hemodynamics during pulsatile and nonpulsatile cardiopulmonary bypass. Method: Near-infrared spectroscopy was used to determine cerebral blood flow and cerebral blood volume (measured as concentration change) in a randomized crossover study. Pulsatile and nonpulsatile flow were used for six 5-minute intervals at each of three different pump flow rates $\left(0.6,1.2\right.$, and $\left.2.4 \mathrm{~L} \cdot \mathrm{m}^{2} \cdot \mathrm{min}^{-1}\right)$ in 40 patients, median age 2 months (range 2 weeks to 20 years 5 months). The relations between pulsatile flow, pump flow rate, cerebral blood flow, hemoglobin concentration change (cerebral blood volume), mean arterial pressure, arterial carbon dioxide tension, and hematocrit value were prospectively examined by means of multivariate analysis. Results: Cerebral blood flow decreased $36 \%$ per $\mathrm{L} \cdot \mathrm{m}^{-2} \cdot \mathrm{min}^{-1}$ decrease in pump flow rate and was associated with changes in mean arterial pressure but did not differ according to pulsatility. Change in hemoglobin concentration was unrelated to changes in pulsatility of pump flow. Conclusion: Cerebral blood flow is related to pump flow rate. Pulsatile flow delivered with a Stöckert pump does not increase cerebral blood flow or alter hemoglobin concentration during cardiopulmonary bypass in children. ( $J$ Thorac Cardiovasc Surg 1997;114:568-77)
In complex congenital heart disease, pump flow is often reduced to improve surgical exposure, but the safe lower limit is uncertain. Conventional car-

From the Departments of Neurosciences, ${ }^{a}$ Anaesthetics, ${ }^{b}$ Epidemiology and Biostatistics, ${ }^{c}$ and Cardiothoracic Surgery, ${ }^{d}$ Institute of Child Health (UCL)/Great Ormond Street Hospital for Children, Great Ormond Street, and Department of Pediatrics and Neonatal Medicine, ${ }^{\circ}$ Royal Postgraduate Medical School, Du Cane Rd., London, United Kingdom.

This work was performed at Great Ormond Street Hospital for Children, London, United Kingdom.

This work was funded by the British Heart Foundation. F.J.K. is funded by the Wellcome Trust.

Received for publication Sept. 23, 1996; revisions requested Nov. 19, 1997; revisions received April 30, 1997; accepted for publication May 2, 1997.

Address for reprints: Fenella J. Kirkham, FRCP, Neurosciences Unit, Institute of Child Health (UCL), Mecklenburgh Square, London WC1N 2AP, United Kingdom.

Copyright (C) 1997 by Mosby-Year Book, Inc.

$0022-5223 / 97 \$ 5.00+0 \quad \mathbf{1 2 / 1 / 8 3 0 7 1}$ diopulmonary bypass (CPB), delivered by a roller or centrifugal pump, is nonpulsatile, although experimental evidence for adverse cerebral effects has been detected. ${ }^{1}$ Pulsatile pumps, which apparently improve systemic, myocardial, and pituitary perfusion, ${ }^{2}$ are available, but whether pulsatile flow holds any advantages for the brain remains a subject of controversy. ${ }^{3-5}$ No previous work has been done in children, partly because appropriate equipment has only recently become available.

If the critical opening pressure of the capillary bed is lower with pulsatile flow, then at low pump flow rates, the capillary bed or parts of it might be "open" during pulsatile flow but effectively "closed" during nonpulsatile flow. Noninvasive near-infrared spectroscopy (NIRS) offers a unique way of investigating this because an overall increase in capillary blood volume, in association with a lower critical opening pressure, would be reflected by an increase in total hemoglobin concentration (HbVol). In addition, cerebral blood flow (CBF) may be measured 
repeatedly by means of a modification of the Fick principle with indocyanine green dye as the tracer. ${ }^{6}$ Using these methods, this study tests the hypothesis that pulsatility affects CBF and cerebral blood volume (CBV) at different pump flow rates.

\section{Patients and methods}

The study was approved by the Research Ethics Committee of the Great Ormond Street Hospital for Children, and written informed consent was obtained from the parents of the children studied.

Patients. Forty patients, 26 cyanotic, median age 2 months (range 2 weeks to 20 years 5 months), undergoing surgical correction of congenital heart defects, were studied. Diagnostic and procedural data are shown in Table I.

Anesthesia. Anesthesia was standardized, with the age and clinical condition of the patient being kept in mind. Premedication was chosen in the light of clinical findings and after discussion with the parents and child. Seven patients received no premedication. Thirteen infants (all $<10 \mathrm{~kg}$ ) received atropine $20 \mathrm{mg} \cdot \mathrm{kg}^{-1}$ by intramuscular injection 45 minutes before the operation. One infant $(<10 \mathrm{~kg}$ ) received an injection of meperidine (INN: pethidine) compound $0.08 \mathrm{ml} \cdot \mathrm{kg}^{-1}$ and atropine $20 \mathrm{mg}$. $\mathrm{kg}^{-1}$ by intramuscular injection 1 hour before the operation. Twelve children $(3.4$ to $10.7 \mathrm{~kg}$ ) received triclofos 30 $\mathrm{mg} \cdot \mathrm{kg}^{-1}$ orally; ten of these children also had atropine 20 $\mathrm{mg} \cdot \mathrm{kg}^{-1}$ by intramuscular injection 90 minutes before the operation. Of the older children $(>15.5 \mathrm{~kg})$, one received morphine $200 \mathrm{mg} \cdot \mathrm{kg}^{-1}$ and scopolamine hydrobromide $10 \mathrm{mg} \cdot \mathrm{kg}^{-1}$ by intramuscular injection 1 hour before the operation, and six were given temazepam 0.25 to $0.5 \mathrm{mg}$. $\mathrm{kg}^{-1}$ by mouth 1 hour before the operation. Induction of anesthesia was by inhalation (nitrous oxide, oxygen, and halothane) or by intravenous thiopental 3 to $5 \mathrm{mg} \cdot \mathrm{kg}^{-1}$ or ketamine $1 \mathrm{mg} \cdot \mathrm{kg}^{-1}$. Thereafter anesthesia was maintained by a generous dose of fentanyl 10 to $40 \mathrm{mg} \cdot \mathrm{kg}^{-1}$ with pancuronium $0.2 \mathrm{mg} \cdot \mathrm{kg}^{-1}$, repeated as required, although this administration was not standardized. The patient's lungs were ventilated by means of intermittent positive-pressure ventilation, initially to normocapnia, with nitrous oxide in oxygen (50:50). Measurements were performed during this maintenance period. Isoflurane $(0 \%$ to $1 \%$ ) was administered before CPB but was not used during CPB.

CPB management. CPB was conducted by means of hypothermic hemodilution techniques with the use of a pulsatile roller pump (Stöckert, Munich, Germany) and a hollow-fiber membrane oxygenator (Minimax, Medtronic U.K. Ltd., Hertz, United Kingdom, or Safemicro, Polystan, Denmark), placed distal to the roller pump. The target hematocrit value was in the range of $22 \%$ to $25 \%$. Nasopharyngeal temperature varied according to clinical need, and the pump flow rate was changed according to protocol. Details of the priming protocols are published elsewhere. ${ }^{7}$ The alpha-stat method of arterial blood gas management was used. Measurements were made during steady-state hypothermic CPB $\left(18^{\circ} \mathrm{C}\right.$ to $\left.25.0^{\circ} \mathrm{C}\right)$. Three patients (patients 3,29 , and 40 ) reached a stable hypothermic temperature of $25^{\circ} \mathrm{C}$, whereas another three patients (patients 9,10 , and 15 ) reached a stable temper- ature of $18^{\circ} \mathrm{C}$; the rest of the patients were cooled to $22^{\circ} \mathrm{C}$. Pulsatile flow settings used were a heart rate of 100 beats $/ \mathrm{min}$. The baseline flow variable was from $0 \%$ to $100 \%$; the setting used was $20 \%$ during the pulsatile phase, with a run time of $50 \%$.

Experimental protocol. The principle of NIRS is that biologic tissues are relatively transparent to light in the near-infrared spectrum $(700$ to $1000 \mathrm{~nm}){ }^{8} \mathrm{CBF}$ can be estimated by means of a modification of the Fick principle that uses indocyanine green dye as an intravascular and nondiffusible tracer. 6 The sum of the changes in deoxygenated hemoglobin and oxygenated hemoglobin concentration gives the change in $\mathrm{HbVol}$ from an arbitrary time. If the hematocrit value is constant during this period, then the change in $\mathrm{HbVol}$ will be proportional to the change in $\mathrm{CBV}$ in the tissue sampled.

A commercial spectrophotometer (NIRO 500, Hamamatsu, Hamamatsu City, Japan) was used. Light at four wavelengths $(776,819,843$, and $913 \mathrm{~nm})$ was conveyed to the child's head via a flexible fiberoptic bundle, which terminated in an optode that was applied to the frontoparietal region of the child's head after induction of anesthesia. Transmitted light emerging was collected via another optode and fiberoptic bundle leading to the photon detector in the spectrophotometer. The distance between the position of the two optodes was measured with mechanical calipers and was always greater than 3 $\mathrm{cm}$. To prevent interference from background light, we wrapped the head in a light-tight cloth. Measurements were made continuously and collected into 0.5 -second time bins. They were displayed instantaneously and stored on computer disk for subsequent analysis. The differential path-length factor, reflecting photon scattering, was 4.39 in children younger than 2 and 5.93 in those older than $2 .{ }^{9}$ The arterial concentration of tracer was optically quantified by using a fiberoptic probe (Pulsion Medizintechnik, Munich, Germany) placed in the arterial line of the CPB circuit at its junction with the aorta. Indocyanine green dye $\left(0.1 \mathrm{mg} \cdot \mathrm{kg}^{-1}\right)$ was injected upstream to this probe. Left-to-right shunts did not affect the study because CBF measurements were taken only when the aorta was crossclamped.

Patients were assigned a program of low, medium, and high flow rates in a random order to be applied during stable hypothermic bypass. No additional time was taken for the measurements to be performed. During each assigned pump flow rate, pulsatile flow was delivered for 5 minutes, followed by 5 minutes of nonpulsatile flow (or vice versa) in a prospective randomized way. The $\mathrm{HbVol}$ for each pump flow rate and pulsatility setting was calculated by taking an average of all the $\mathrm{HbVol}$ measurements for 3 minutes after the pump flow change, before making a $\mathrm{CBF}$ measurement. $\mathrm{CBF}$ was measured before the pulsatility change, after 4 minutes of the assigned pump flow rate. Each CBF measurement takes approximately 10 seconds. During each CBF measurement, nasopharyngeal temperature, pump flow, mean arterial pressure, arterial carbon dioxide tension $\left(\mathrm{PaCO}_{2}\right)$, and hematocrit values were measured. A schematic representation of the protocol is shown in Fig. 1. Thus one patient might have half, quarter, and full flow with nonpulsatile followed by pul- 
Table I. Diagnostic and procedural data

\begin{tabular}{|c|c|c|c|}
\hline Patient & Age (yr) & Diagnosis & Operation \\
\hline 1 & 0.98 & TOF & Repair \\
\hline 2 & 0.75 & TOF & Repair \\
\hline 3 & 0.75 & TOF & Repair \\
\hline 4 & 0.75 & $\begin{array}{l}\text { Double-inlet LV, TGA after } \\
\text { arterial switch, CoA, hypo- } \\
\text { plastic aortic arch, subpul- } \\
\text { monary obstruction }\end{array}$ & Bidirectional Glenn shunt \\
\hline 5 & 0.06 & TGA & Repair \\
\hline 6 & 0.75 & Multiple VSD & Repair and debanding \\
\hline 7 & 0.1 & AVSD, Down's syndrome & Repair \\
\hline 8 & 0.2 & AVSD, Down's syndrome & Repair \\
\hline 9 & 0.25 & TGA, VSD & Repair \\
\hline 10 & 0.01 & TGA & Repair \\
\hline 11 & 3.08 & TA & TCPC \\
\hline 12 & 0.25 & $\begin{array}{l}\text { Anomalous left coronary } \\
\text { artery }\end{array}$ & Repair \\
\hline 13 & 0.12 & Double-inlet LV, TGA, VSD & Palliative arterial switch \\
\hline 14 & 0.83 & $\begin{array}{l}\text { CoA, VSD, supramitral } \\
\text { valve, LA ring }\end{array}$ & $\begin{array}{l}\text { Atrial septectomy, debanding, } \\
\text { disconnect MPA, central } \\
\text { shunt }\end{array}$ \\
\hline 15 & 0.3 & DORV & Central shunt \\
\hline 16 & 11.1 & $\begin{array}{l}\text { Double-inlet LV with trans- } \\
\text { posed great arteries and } \\
\text { VSD; previous bidirec- } \\
\text { tional Glenn shunt }\end{array}$ & Completion of TCPC \\
\hline 17 & 0.83 & TOF & Repair \\
\hline 18 & 2.08 & TR & Tricuspid valve repair \\
\hline 19 & 2.08 & $\mathrm{TR}$ & Tricuspid valve replacement \\
\hline 20 & 8.33 & DIRV, DORV & TCPC \\
\hline 21 & 0.42 & TOF & Repair \\
\hline 22 & 0.17 & TGA & Repair \\
\hline 23 & 0.66 & VSD & Repair, debanding \\
\hline 24 & 3.66 & Restrictive cardiomyopathy & Heart transplant \\
\hline 25 & 0.75 & TOF & Repair \\
\hline 26 & 14.58 & $\begin{array}{l}\text { Down's syndrome, previous } \\
\text { TOF repair }\end{array}$ & RV-PA homograft \\
\hline 27 & 8.5 & PAtr, VSD, MAPCAs & $\begin{array}{l}\text { Replacement RV-PA } \\
\text { homograft }\end{array}$ \\
\hline 28 & 15.5 & $\mathrm{AR}$ & Ross procedure \\
\hline 29 & 20 & PAtr, VSD, MAPCAs & Complex unifocalization \\
\hline 30 & 0.42 & AVSD & Repair \\
\hline 31 & 0.08 & TGA & Arterial switch \\
\hline 32 & 0.01 & TGA & Arterial switch \\
\hline 33 & 0.08 & TGA & Arterial switch \\
\hline 34 & 0.85 & TOF & Repair \\
\hline 35 & 0.52 & $\begin{array}{l}\text { PAtr, absent MPA, hypo- } \\
\text { plastic RV }\end{array}$ & $\begin{array}{l}\text { TCPC and closure of coro- } \\
\text { nary fistulas }\end{array}$ \\
\hline 36 & 0.02 & TGA & Arterial switch \\
\hline 37 & 0.02 & TGA & Arterial switch \\
\hline 38 & 0.03 & VSD, PFO & Repair \\
\hline 39 & 1.33 & TOF & Repair \\
\hline 40 & 0.58 & RVOTO, VSD & Repair \\
\hline
\end{tabular}

$A R$, Aortic regurgitation; $A V S D$, atrioventricular septal defect; $C O A$, coarctation of the aorta; $D I R V$, double-inlet right ventricle; $D O R V$, double-outlet right ventricle; $L A$, left atrial; $L V$, left ventricle; $M A P C A s$, multiple aortopulmonary collateral arteries; $M P A$, main pulmonary artery; $P A$, pulmonary artery; $P A t r$, pulmonary atresia; $P F O$, patent foramen of ovale; $R V$, right ventricle; $R V O T O$, right ventricular outflow tract obstruction; $T A$, truncus arteriosus; $T C P C$, total cavopulmonary connection; TGA, transposition of the great arteries; $T O F$, tetralogy of Fallot; $T R$, tricuspid regurgitation; VSD, ventricular septal defect. 


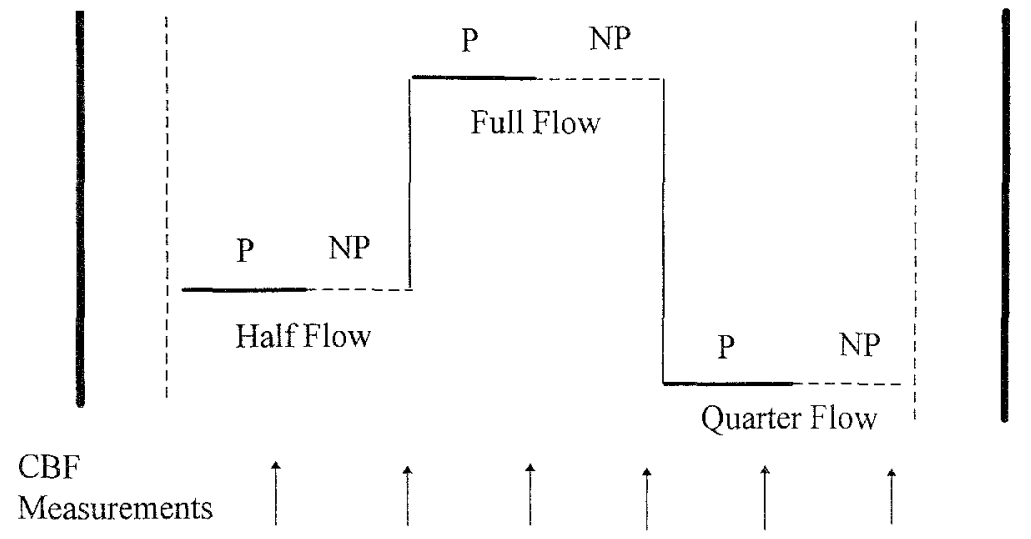

Fig. 1. Schematic representation of one of the protocols used. The sequence of flow rates and pulsatile and nonpulsatile flow were each prospectively randomly assigned during stable hypothermic bypass. The pump flow rates were full flow $\left(2.4 \mathrm{~L} \cdot \mathrm{m}^{2} \cdot \mathrm{min}^{-1}\right)$, half flow $\left(1.2 \mathrm{~L} \cdot \mathrm{m}^{2} \cdot \mathrm{min}^{-1}\right)$, and quarter flow $(0.6 \mathrm{~L}$ $\left.\cdot \mathrm{m}^{2} \cdot \mathrm{min}^{-1}\right)$. CBF was measured before the pulsatility of pump fiow was changed, and the change in hemoglobin concentration was measured continuously. Bold vertical lines represent the beginning and end of the operation. Vertical dotted lines represent the hypothermic period. $P$, Pulsatile flow; NP, nonpulsatile flow.

satile flow and the next patient might have full, quarter, and half flow with pulsatile followed by nonpulsatile flow.

A range-gated pulsed-wave Doppler probe, with a frequency of $2 \mathrm{MHz}$, was used in one patient. The transducer probe was placed over the zygoma area, anterior to the tragus, to display middle cerebral artery flow during pulsatile and nonpulsatile CPB flow and when the heart was beating, and the waveform was examined.

Statistical analysis. Multiple linear regression models were used to determine the extent to which $\mathrm{HbVol}$ and CBF were related to pulsatility and pump flow rate. CBF was logged before modeling. A series of dummy variables were used to model patient-specific variability in the outcomes, thus accounting for differences resulting from age, cyanosis, and other patient-specific factors. Mean arterial pressure, $\mathrm{PaCO}_{2}$, arterial oxygen tension $\left(\mathrm{PaO}_{2}\right)$, hematocrit value, and temperature were then entered into the model to adjust for the potentially confounding effect of within-individual associations between these variables and the outcomes. The relationships between CBF and $\mathrm{HbVol}$ with pulsatility and pump flow are represented after adjusting for all of the potential confounders. Computations were made with the use of the SPSS statistical package (SPSS, Inc., Chicago, Ill.).

\section{Results}

Clinical outcome. Patients $1,8,14,20$, and 29 died, patient 1 of pneumonia, patient 8 of low cardiac output, patient 14 of systemic ventricular failure, patient 20 of cardiac failure, and patient 29 of pulmonary hemorrhage. Patients 2 and 6 required permanent pacemakers for complete heart block. Patient 13 had a left pneumothorax, patient 21 had partial dehiscence of a ventricular septal defect patch dehiscence (which necessitated another oper- (i)

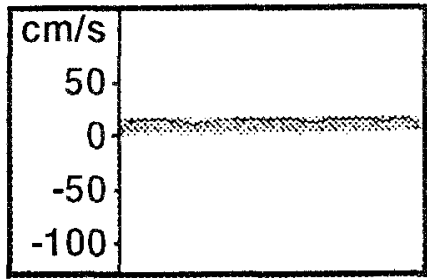

(ii)

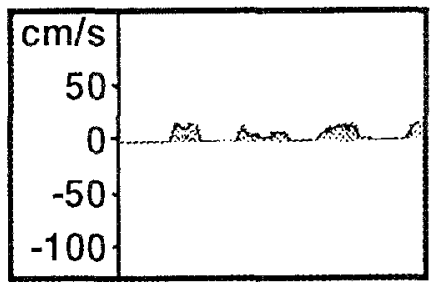

(iii)

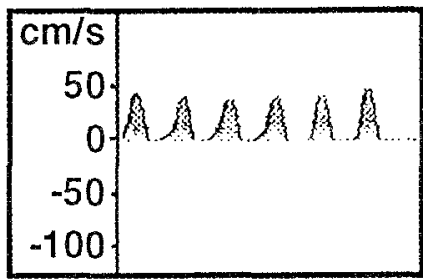

Fig. 2. Reproduction of transcranial Doppler display in one infant. Right middle cerebral artery. i, During full continuous CPB flow. ii, During full pulsatile CPB flow. iii, With a beating heart before being weaned from $\mathrm{CPB}$.

ation), patient 25 had mediastinitis, and patient 35 had a chylothorax on the left side and required a permanent pacemaker for sinus bradycardia. The other patients made uneventful recoveries. No neu- 


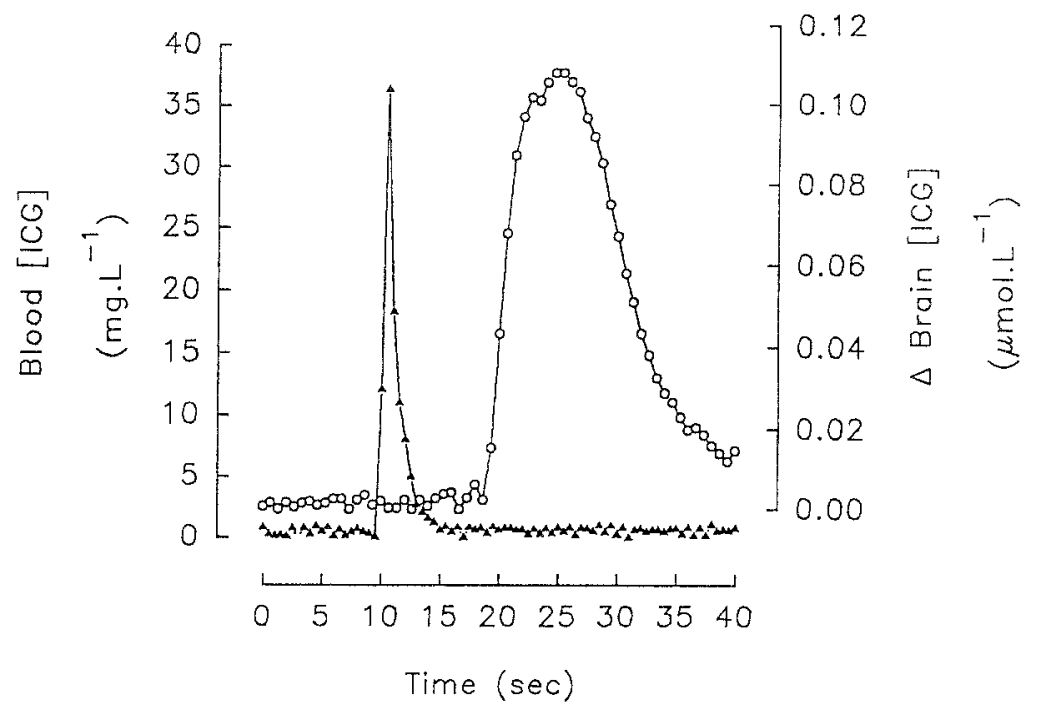

Fig. 3. Blood $(\mathbf{\Lambda})$ and brain $(O)$ concentrations of indocyanine green dye $(I C G)$ after injection of dye into the $\mathrm{CPB}$ circuit. The use of these data for calculating CBF is described in the text.

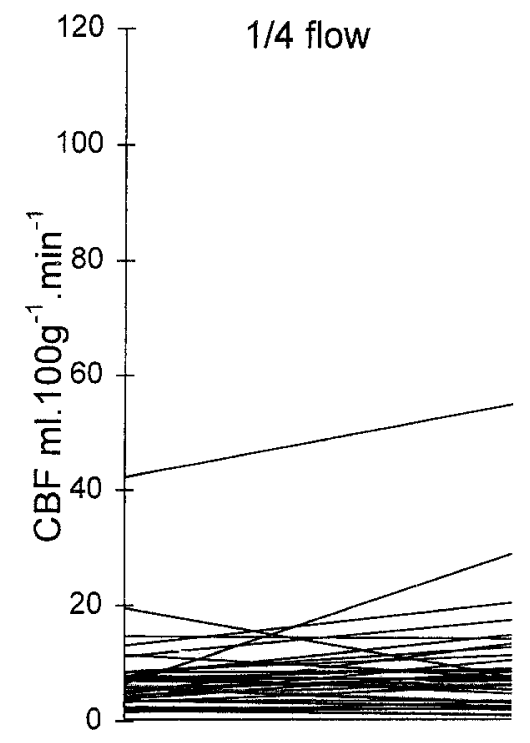

Pulsatile Nonpulsatile
$1 / 2$ flow

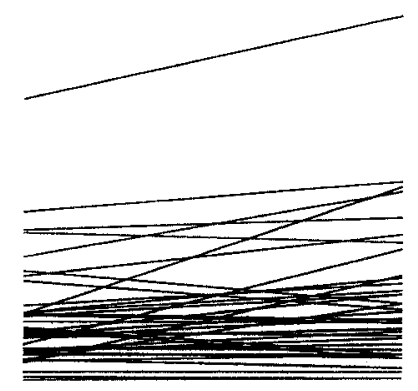

Pulsatile Nonpulsatile
Full flow

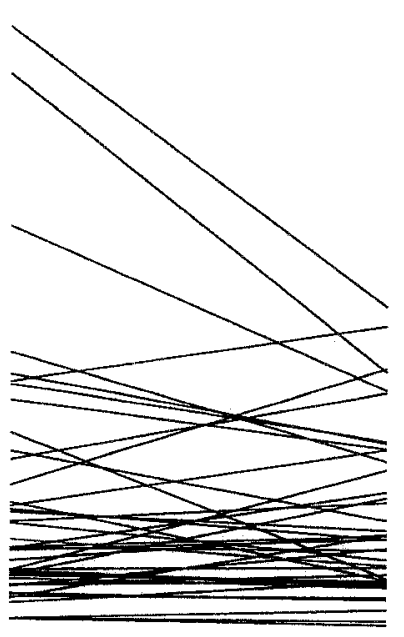

Pulsatile Nonpulsatile

Fig. 4. Graph of CBF measurements made at pulsatile and nonpulsatile flows at quarter, half, and full pump flow rates. CBF did not vary according to pulsatility at these pump flow rates.

rologic problems developed in the postoperative period.

Doppler measurements. In the one patient studied by Doppler ultrasonography, while nonpulsatile pump flow did not produce a pulsatile waveform, pulsatile pump flow did, but this was of lower amplitude than that produced by a beating heart (Fig. 2).
CBF and CBV measurements. An example of the change of indocyanine green dye concentrations in arterial and cerebral blood during a measurement of CBF is shown in Fig. 3. A total of 230 measurements were made during stable hypothermia in the 40 patients. Fig. 4 is a graph of CBF measurements at pulsatile and nonpulsatile flow at quarter, half, and full pump flow rates. CBF did not tend to vary 


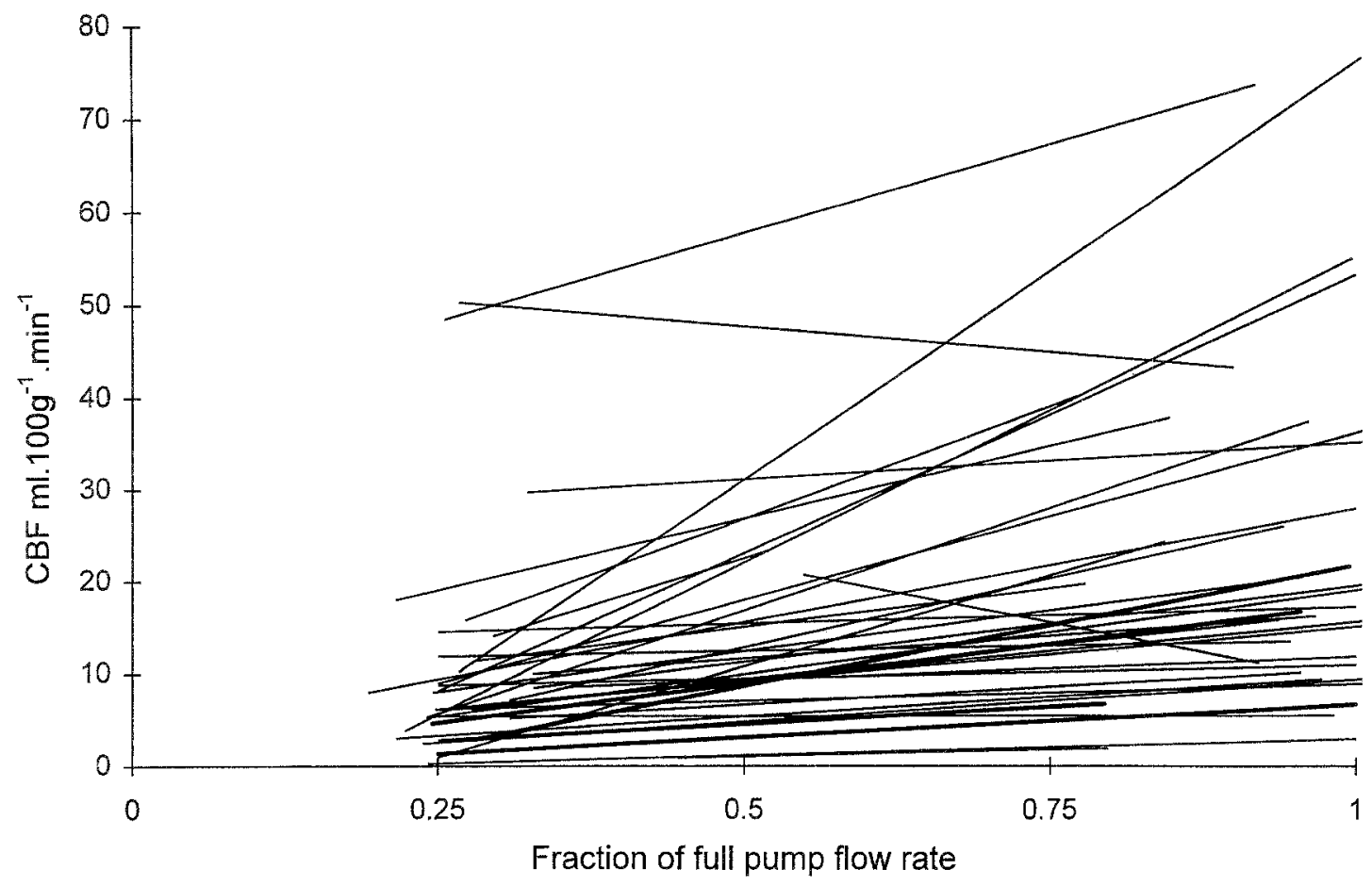

Fig. 5. Graph showing for each patient the best regression lines describing the relationship between CBF and pump flow rate using both measurements at pulsatile and nonpulsatile pump flow.

Table II. The relation between $C B F, H b V o l$, and independent variables

\begin{tabular}{|c|c|c|c|c|c|c|}
\hline Independent variable & Percent change in $C B F$ & $95 \% C L(\%)$ & $p$ Value & Change in $\mathrm{HbVol}$ & $95 \% C L$ & p Value \\
\hline Mean arterial pressure & $2.2 \%$ per $\mathrm{mm} \mathrm{Hg}$ & $+1.7,+2.5$ & $<0.00005$ & $\begin{array}{l}0.06 \mu \mathrm{mol} \cdot \mathrm{L}^{-1} \text { per } \\
\mathrm{mm} \mathrm{Hg}\end{array}$ & $+0.04,+0.08$ & $<0.00005$ \\
\hline Hematocrit value & $-1.4 \%$ per $\%$ change & $-2.6,+0.06$ & 0.04 & $\begin{array}{l}-0.02 \mu \mathrm{mol} \cdot \mathrm{L}^{-1} \text { per } \\
\quad \% \text { change }\end{array}$ & $-0.08,+0.04$ & 0.50 \\
\hline $\mathrm{PaCO}_{2}$ & $1.8 \%$ per $\mathrm{mm} \mathrm{Hg}$ & $+0.6,+3.1$ & 0.003 & $\begin{array}{l}0.06 \mu \mathrm{mol} \cdot \mathrm{L}^{-1} \text { per } \\
\mathrm{mm} \mathrm{Hg}\end{array}$ & $+0.004,+0.11$ & 0.03 \\
\hline Termperature & $1.7 \%$ per ${ }^{\circ} \mathrm{C}$ & $-2.4,+5.9$ & 0.42 & $\begin{array}{l}0.01 \mu \mathrm{mol} \cdot \mathrm{L}^{-1} \text { per } \\
{ }^{\circ} \mathrm{C}\end{array}$ & $-0.18,+0.18$ & 0.98 \\
\hline $\mathrm{PaO}_{2}$ & $0.07 \%$ per $\mathrm{mm} \mathrm{Hg}$ & $-0.03,+0.16$ & 0.20 & $\begin{array}{l}0.001 \mu \mathrm{mol} \cdot \mathrm{L}^{-1} \text { per } \\
\mathrm{mm} \mathrm{Hg}\end{array}$ & $-0.003,+0.005$ & 0.61 \\
\hline Pump flow & $\begin{array}{l}36 \% \text { per } \mathrm{L} \cdot \mathrm{m}^{-2} \cdot \mathrm{min}^{-1} \\
\text { change in pump flow rate }\end{array}$ & $+21.6,+53.5$ & $<0.00005$ & $\begin{array}{l}0.8 \mu \mathrm{mol} \cdot \mathrm{L}^{-1} \\
\text { per } \mathrm{L} \cdot \mathrm{m}^{-2} \cdot \mathrm{min}^{-1} \\
\text { change in pump } \\
\text { flow rate }\end{array}$ & $+0.41,+1.20$ & 0.0001 \\
\hline $\begin{array}{l}\text { Pulsatile pump flow/ } \\
\text { continuous pump } \\
\text { flow }\end{array}$ & $\begin{array}{l}4.5 \% \text { increase from pulsatile } \\
\text { flow to nonpulsatile flow }\end{array}$ & $-7.1,+17.6$ & 0.46 & $\begin{array}{l}0.07 \mu \mathrm{mol} \cdot \mathrm{L}^{-1} \text { in- } \\
\text { crease from pulsa- } \\
\text { tile flow to nonpul- } \\
\text { satile flow }\end{array}$ & $-0.47,+0.61$ & 0.80 \\
\hline
\end{tabular}

$C L$, Confidence limits.

according to pulsatility at these pump flow rates. Pulsatile/continuous pump flow relates to the use of the pulsatile setting on the Stöckert pump. Fig. 5 shows the best-fit regression lines for all the CBF measurements at different flow rates for each patient. Table II contains the results of the multiple linear regression of CBF on the predictor variables. $\mathrm{HbVol}$ and $\mathrm{CBF}$ differed significantly between pa- 


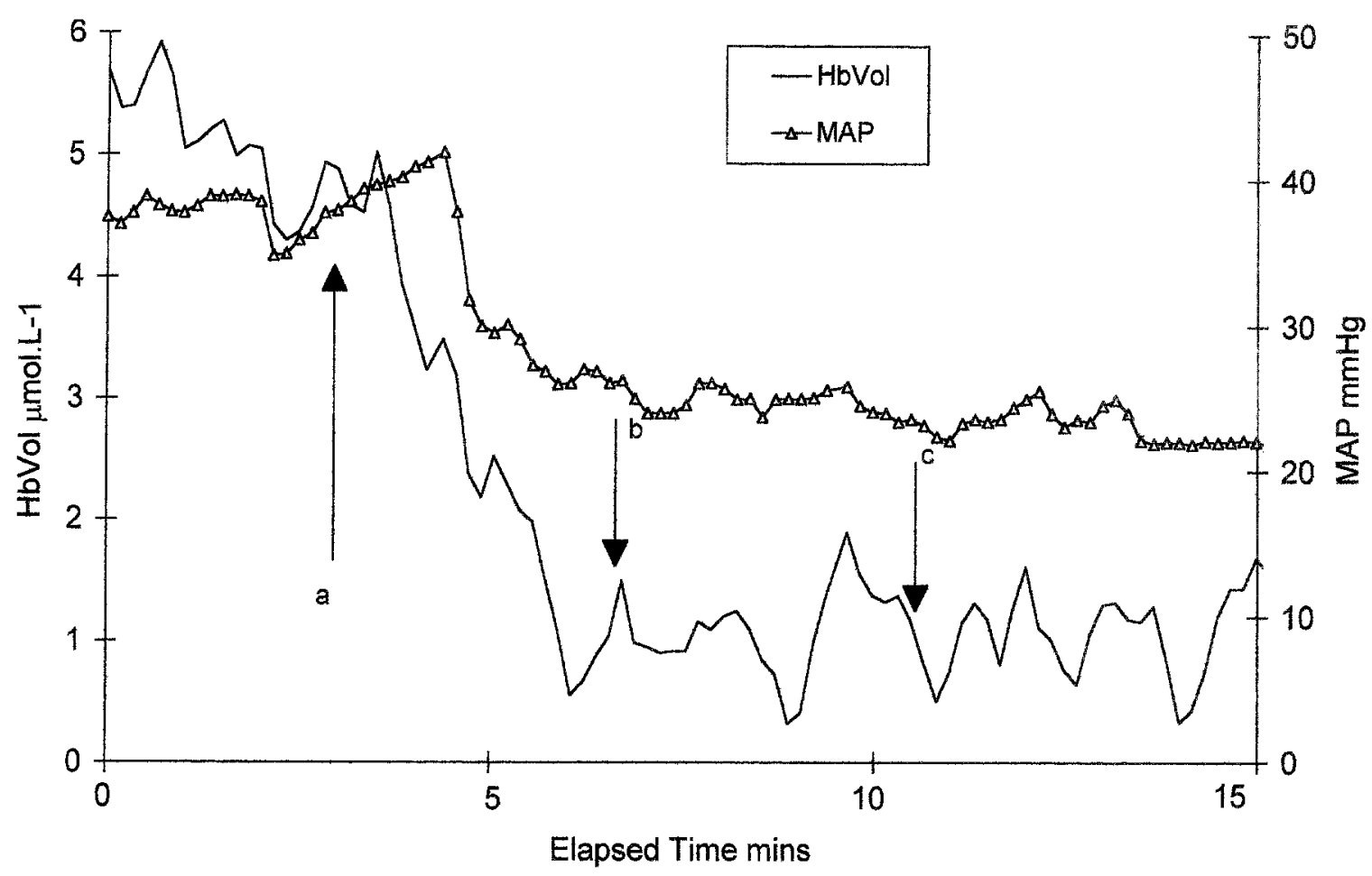

Fig. 6. Changes in HbVol and mean arterial pressure $(M A P)$ when pump flow rate was changed from $(a)$ pulsatile half pump flow rate to $(b)$ nonpulsatile quarter pump flow rate and to $(c)$ pulsatile quarter pump flow rate for one patient. HbVol falls with mean arterial pressure from $a$ to $b$ as the two are associated, and mean arterial pressure falls with pump flow rate as the two covary.

tients. The average $\mathrm{HbVol}$ ranged from -14.39 to $4.95 \mathrm{ml} \cdot 100 \mathrm{gm}^{-1} \cdot \min ^{-1}$ and the average CBF from 1.04 to $57.39 \mu \mathrm{mol} \cdot \mathrm{L}^{-1}$. Temperature, mean arterial pressure, $\mathrm{PaCO}_{2}$, and $\mathrm{PaO}_{2}$ varied between individuals, regardless of pulsatility and pump flow status. Table II shows the relationship between these variables and $\mathrm{HbVol}$ and $\mathrm{CBF}$ after accounting for individual variation. Associations between pulsatility, pump flow rate, and the outcomes after adjustment for individual variability, temperature, mean arterial pressure, hematocrit value, $\mathrm{PaCO}_{2}$, and $\mathrm{PaO}_{2}$ are also given in the table. Mean arterial pressure and $\mathrm{PaCO}_{2}$ were significantly associated with $\mathrm{CBF}$. Mean arterial pressure tended to be higher at higher pump flow rates $(p<0.001)$. CBF decreased $36 \%$ per $\mathrm{L} \cdot \mathrm{m}^{-2} \cdot \mathrm{min}^{-1}$ decrease in pump flow rate $(95 \%$ confidence intervals [CI $] 21.6,53.5)$, after taking into account all the potential confounders (i.e., differences between individuals and the effects of changes in mean arterial pressure, hematocrit value, $\mathrm{PaCO}_{2}, \mathrm{PaO}_{2}$, and temperature within individuals). Hematocrit value was significantly associated with CBF ( $p=0.04,95 \%$ CI $-2.6,-0.06)$.
Pulsatility was not significantly associated with $\mathrm{CBF}$, nor was there a significant interaction between pump flow rate and pulsatility $(p=0.3)$.

The average standard deviation for measurements of change in $\mathrm{HbVol}$ in the study group during the 5-minute period before the change of pump flow rate and pulsatility was $0.75 \mathrm{mmol} \cdot \mathrm{L}^{-1}$. Fig. 6 shows the change in $\mathrm{HbVol}$ and mean arterial pressure when the pump flow rate was changed from pulsatile half flow to nonpulsatile quarter flow to pulsatile quarter flow for one patient. Fig. 7 shows the relative change in $\mathrm{HbVol}$ from pulsatile to nonpulsatile flow at quarter, half, and full pump flow rates. Table II shows the relation between $\mathrm{HbVol}$ and the independent variables. Mean arterial pressure and pump flow rate are significantly associated with $\mathrm{HbVol}$. After similar adjustment, $\mathrm{HbVol}$ decreased by $0.8 \mu \mathrm{mol} \cdot \mathrm{L}^{-1}$ per $\mathrm{L} \cdot \mathrm{m}^{-2} \cdot \mathrm{min}^{-1}$ change in pump flow rate $(95 \%$ CI $0.41,1.20)$. Pulsatility, $\mathrm{PaCO}_{2}$, and hematocrit value did not add further to the model.

The association between pump flow, pulsatility, and the outcomes was similar for both cyanotic and acyanotic patients and was unchanged when the 


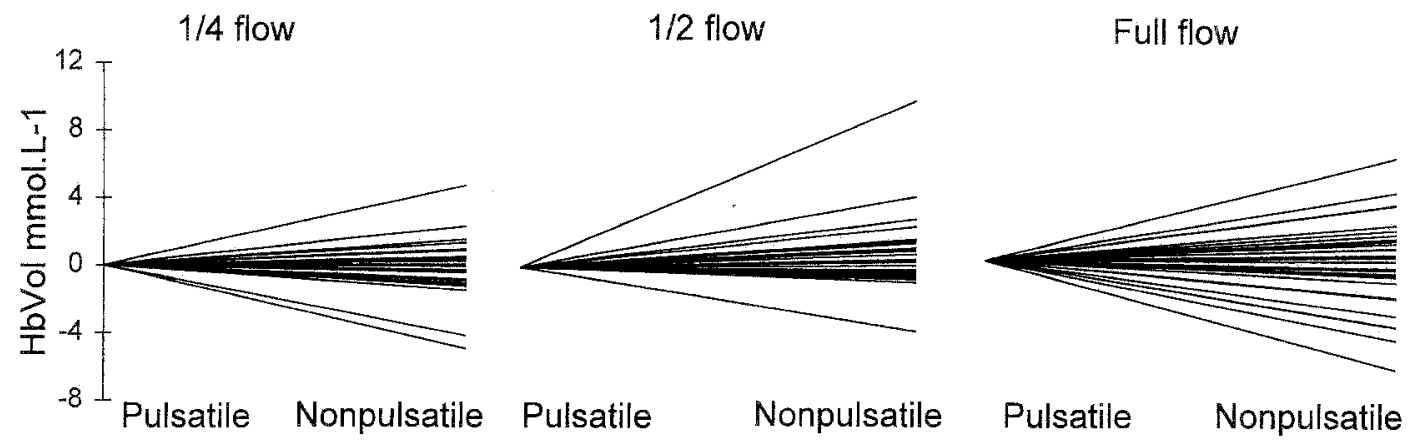

Fig. 7. Graph showing the change in $\mathrm{HbVol}$ from pulsatile flow to nonpulsatile flow at a quarter, half, and full pump flow rate in each patient. $\mathrm{HbVol}$ did not vary according to pulsatility at these pump flow rates.

nine children over the age of 2 years were excluded from the analysis.

\section{Discussion}

This study yielded two major findings. First, CBF fell with decreasing pump flow rate, $\mathrm{PaCO}_{2}$, and mean arterial pressure. Mean arterial pressure covaried with pump flow rate, suggesting that autoregulation was abolished. Second, pulsatile flow did not influence $\mathrm{CBF}$ or $\mathrm{HbVol}$ at any pump flow. The methodologic issues will be addressed before discussion of the findings.

The CBF technique uses NIRS and a modification of the Fick principle. ${ }^{6}$ The initial description involved the use of oxygen as a tracer and has been validated in neonates. ${ }^{10}$ For applications, such as $\mathrm{CPB}$, in which it may be difficult to change oxygen tension or in which the signal-to-noise ratio for measurement of the input function must be improved, a more recent modification for which indocyanine green is used as the tracer ${ }^{11}$ is preferred. Recent data from our laboratory indicate that $\mathrm{CBF}$ measurements obtained with this technique are highly correlated with those obtained with the use of microspheres in a piglet model. Although no validation studies have been conducted yet in human beings, the technique appears to be able to measure change in CBF. ${ }^{12}$ NIRS is a sensitive technique for observation of changes in $\mathrm{HbVol}$ and can detect changes of $0.5 \mathrm{mmol}$ or less. It is uniquely suited for investigating the relatively small changes in $\mathrm{CBV}$ expected with capillary recruitment. CBV changes can be inferred from the change in $\mathrm{HbVol}$, assuming the hematocrit value is constant during periods of measurement. ${ }^{13}$ The mean change in hematocrit value between pulsatile and nonpulsatile pump flow in this study was $0.26 \%$, standard deviation $1.74 \%$, which satisfies this constraint.

Anesthesia was chosen so that there would be no confounding effect on CBF. The variations in premedication are unlikely to have affected CBF measurements. Ketamine and halothane were used only on induction, at least 40 minutes before measurements of $\mathrm{CBF}$.

Pump flow rate. Low pump flow can reduce noncoronary collateral circulation and thus improve myocardial preservation. ${ }^{14}$ At times, adequate surgical exposure may require very low pump flow rates to reduce venous return to the open heart, particularly in children with congenital heart disease in whom the repairs may be complex. The important question is whether a safe minimum pump flow exists, below which brain damage is likely to occur.

There is evidence for an ischemic threshold from animal experiments conducted during $\mathrm{CPB}$, at least at very low pump flow of $5 \mathrm{ml} \cdot \mathrm{kg}^{-1} \cdot \mathrm{min}^{-1}$. $^{15}$ Although in clinical practice pump flow rates are not as low as these, $\mathrm{CBF}$ might fall below that required for the metabolic demand of the tissue. The relation between $\mathrm{CBF}$ and pump flow rate remains controversial, despite a number of investigations in human beings, with various forms of acid-base management. ${ }^{16-19}$ Those who have claimed that changing pump flow has no effect have studied adults and have reduced pump flow to no lower than half of the calculated full requirement. Pediatric studies are clearly justified, particularly because pump flows tend to be lower. Our data confirm the findings of Kern and associates ${ }^{19}$ in children, that a significant relation exists between $\mathrm{CBF}$ and pump flow rate when alpha-stat $\mathrm{pH}$ management is used, with covariance between pump flow rate and mean arterial 
pressure. Any beneficial effect at low pump flow of increasing blood pressure pharmacologically, changing $\mathrm{pH}$ strategy, or otherwise modifying $\mathrm{CPB}$ could be addressed by means of the NIRS technique.

Pulsatile flow. In the animal literature, the controversy focuses on whether pulsatile flow yields any benefits in terms of cerebral hemodynamics. ${ }^{3,4,20}$ It has been suggested that the critical opening pressure of the capillary bed is lower with pulsatile than with nonpulsatile flow, ${ }^{21}$ which might be important in maintaining adequate tissue perfusion at the low pump flows used during CPB. This might explain the higher CBF during pulsatile pump flow at cerebral perfusion pressures below $50 \mathrm{~mm} \mathrm{Hg}$ in dogs. ${ }^{22}$ This higher CBF has not, however, been reproduced in rabbits. ${ }^{4}$ Species differences do exist, which means that these questions should be addressed in human beings.

Our data show no difference in CBF between pulsatile and nonpulsatile flow, which is consistent with the findings of the only previous human studies and with the studies of Hindman and colleagues, ${ }^{4}$ who argued that their lapine model might reflect the human situation more closely than the canine studies. The change in HbVol was similarly not significantly different for pulsatile and nonpulsatile pump flow at the three measured flow rates. There may be a difference between children and adults. Young patients have more compliant vessels and a lower vascular resistance; thus pulsatile flow, which decreases mean arterial pressure, ${ }^{23}$ may hold no advantage. ${ }^{24}$ However, preliminary studies from our group suggest that pulsatile flow does not increase CBF in adults either. ${ }^{25}$

It has been argued that a CPB machine switched to "pulsatile flow" may not produce a truly pulsatile waveform and will almost certainly behave differently from the living heart. In this study we used the Stöckert pump, because it is the one most frequently used in adult and pediatric CPB and is considered to be capable of delivering pulsatile flow, although it generates only $12.4 \%$ of pulsatile power of a living heart. ${ }^{26}$ In addition, the membrane oxygenators now used have compliant membrane components and tend to absorb much of the energy generated by the pulsatile pump. The aim of this study was to observe the effect of a pump marketed to deliver pulsatile flow during $\mathrm{CBF}$ and $\mathrm{CBV}$ and not to compare the waveforms obtained by different flow levels between patients. The precise waveform may be of little importance, ${ }^{4}$ but Doppler recording confirmed a pulsatile waveform in the middle cerebral artery. It is possible that the arbitrary time of 5 minutes before the pulsatility of pump flow was changed, chosen to ensure that each of the six randomized conditions could be achieved during the relatively short CPB period, did not allow for any significant effects to become apparent. Further studies using alternative pumps or longer time periods, but using the same methods, could be planned.

In summary, we have investigated the relation of $\mathrm{CBF}$ to several important potential predictors. Mean arterial pressure covaries with changes in pump flow rate and is associated with CBF. Pump flow rate is significantly associated with CBF after taking into account any changes that could be attributed to differences in mean arterial pressure. $\mathrm{CBF}$ is also associated with $\mathrm{PaCO}_{2}$ but not pulsatility delivered by the Stöckert pump. HbVol is related to mean arterial pressure and pump flow rate but not to pulsatility. These data do not support a change to use of pulsatile pump flow with a Stöckert pump in children.

We thank M. de Leval, M. Davis, R. Maynard, G. Walsh, A. Dale, nurses, and operating department assistants at the Great Ormond Street Hospital for children, for their assistance and cooperation.

\section{REFERENCES}

1. Matsumo T, Wolferth CC Jr, Perlman MH. Effects of pulsatile and non-pulsatile perfusion upon cerebral and conjunctival microcirculation in the dog. Am Surg 1971;37: 61-4.

2. Taylor KM, Wright GS, Bain WH, Caves PK, Beastall GH. Comparative studies of pulsatile and nonpulsatile flow during cardiopulmonary bypass. III. Anterior pituitary response to thyrotrophin releasing hormone. J Thorac Cardiovasc Surg 1978;75:579-84.

3. Dernevik L, Arvidsson S, William-Olsson G. Cerebral perfusion in dogs during pulsatile and nonpulsatile extracorporeal circulation. J Cardiovasc Surg 1985;26:32-5.

4. Hindman BJ, Dexter F, Ryu KH, Smith T, Cutkomp J. Pulsatile versus nonpulsatile cardiopulmonary bypass. Anesthesiology 1994;80:1137-47.

5. Henze T, Stephan H, Sonntag H. Cerebral dysfunction following extracorporeal circulation for aortocoronary bypass surgery: no differences in neuropsychological outcome alter pulsatile versus nonpulsatile flow. Thorac Cardiovasc Surg 1990;38:65-8.

6. Edwards AD, Richardson C, van der Zee $\mathrm{P}$, et al. Measurement of hemoglobin flow and blood flow by near-infrared spectroscopy. J Appl Physiol 1993;75:1884-89.

7. Huskisson L, Elliott MJ. Prime composition. In: Jonas RA, Elliott MJ, editors. Cardiopulmonary bypass in neonates, infants and young children. 1st ed. Oxford: ButterworthHeinemann Ltd.; 1994. p. 186-97.

8. Jobsis FF. Noninvasive infrared monitoring of cerebral and 
myocardial oxygen sufficiency and circulatory parameters. Science 1977;198:1264-7.

9. van der Zee P, Cope M, Arridge SR, et al. Experimentally measured optical pathlengths for the adult head, calf and forearm and the head of the newborn infant as a function of interoptode spacing. Adv Exp Med Biol 1992;316:143-53.

10. Skov L, Pryds O, Greisen G. Estimating cerebral blood flow in newborn infants: comparison of near infrared spectroscopy and ${ }^{133}$ Xe clearance. Pediatr Res 1991;30:570-3.

11. Roberts I, Fallon P, Kirkham FJ, et al. Estimation of cerebral blood flow with near infrared spectroscopy and indocyanine green. Lancet 1993;342:1425.

12. Chow G, Roberts I, Fallon P, et al. The relation between arterial oxygen tension and cerebral blood flow during cardiopulmonary bypass. Eur J Cardiothorac Surg 1997;11: $633-9$.

13. Wyatt JS, Cope M, Delpy DT, et al. Quantitation of cerebral blood volume in human infants by near-infrared spectroscopy. J Appl Physiol 1990;68:1086-91.

14. Sotainemi KA, Monanen H, Hokkanen TE. Long term cerebral outcome after open heart surgery: a five year neuropsychological study. Stroke 1986;17:410-6.

15. Swain JA, McDonald TJ Jr, Griffth PK, Balaban RS, Clark RE, Ceckler T. Low-flow hypothermic cardiopulmonary bypass protects the brain. J Thorac Cardiovasc Surg 1991;102: 76-83.

16. Govier AV, Reves JG, McKay RD, Smith LR, Adams M, Freeman AM. Factors and their influence on regional cerebral blood flow during nonpulsatile cardiopulmonary bypass. Ann Thorac Surg 1984;38:592-600.

17. Rogers AT, Prough DS, Roy RC, et al. Cerebrovascular and cerebral metabolic effects of alterations in perfusion flow rate during hypothermic cardiopulmonary bypass in man. $\mathbf{J}$ Thorac Cardiovasc Surg 1992;103;363-8.
18. Soma Y, Hirotani $T$, Yozu K, et al. A clinical study of cerebral circulation during extracorporeal circulation. J Thorac Cardiovasc Surg 1989;97:187-93.

19. Kern FH, Ungerleider RM, Reves JG, et al. Effect of altering pump flow rate on cerebral blood flow and metabolism in infants and children. Ann Thorac Surg 1993; 56:1366-72.

20. Onoe M, Mori A, Watarida S, et al. The effect of pulsatile perfusion on cerebral blood flow during profound hypothermia with total circulatory arrest. J Thorac Cardiovasc Surg 1994;108:119-25.

21. Watanabe T, Orita H, Kobayashi M, Washio M. Brain tissue $\mathrm{pH}$, oxygen tension, and carbon dioxide tension in profoundly hypothermic cardiopulmonary bypass: comparative study of circulatory arrest, nonpulsatile low-flow perfusion, and pulsatile low-flow perfusion. J Thorac Cardiovasc Surg 1989;97: 396-401.

22. Sadahiro M, Haneda K, Mohri $H$. Experimental study of cerebral autoregulation during cardiopulmonary bypass with or without pulsatile perfusion. J Thorac Cardiovasc Surg 1994;108:446-54.

23. Dunn J, Kirsch M, Harness J, Carroll M, Sloan H. Hemodynamic, metabolic and hematological effects of pulsatile cardiopulmonary bypass. J Thorac Cardiovasc Surg 1974;68:13847.

24. Mavroudis C. To pulse or not to pulse. Ann Thorac Surg 1978;25:259-71.

25. Chow $G$, Roberts IG, Harris D, Wilson J, Elliott MJ, Edwards AD, Kirkham FJ. Stöckert roller pump generated pulsatile flow: cerebral metabolic changes in adult cardiopulmonary bypass. Perfusion 1997;12:18-9.

26. Wright $\mathbf{G}$. The hydraulic power outputs of pulsatile and nonpulsatile cardiopulmonary bypass pumps. Perfusion 1988; $3: 251-62$. 